\title{
EXPERIMENTAL RESEARCH ON ENERGY RELEASE CHARACTERISTICS OF WATER-BEARING SANDSTONE ALONGSHORE WHARF
}

\author{
Shuren Wang ${ }^{1,2}$, Prof. Dr \\ Yanhai Zhao ${ }^{1,2}$, PhD Candidate, ME \\ Zhengsheng Zou ${ }^{1}$, Prof. Dr \\ Huihui Jia ${ }^{3}$, ENGR ME \\ ${ }^{1}$ International Joint Research Laboratory of Henan Province for Underground Space Development and \\ Disaster Prevention, Henan Polytechnic University, Jiaozuo, Henan 454003, China \\ ${ }^{2}$ Henan Key Laboratory for Green and Efficient Mining \& Comprehensive Utilization of Mineral \\ Resources, Henan Polytechnic University, Jiaozuo, Henan 454003, China \\ ${ }^{3} 514$ Brigade of North China Geological Exploration Bureau, Chengde, Hebei 067000, China
}

\begin{abstract}
It is important to evaluate the deformation and failure of sandstone in the foundation engineering of coast, river bank and lake shore. While the deformation and failure of sandstone is a comprehensive result of energy release and dissipation, and energy release is the internal reason which leads to global failure of the sandstone. The experimental analysis is conducted on the character of energy revolution of the sandstone specimen by rating loading and unloading, and the catastrophe model is followed in analyzing elastic strain energy accumulation and release in rock deformation and failure. The index based on elastic energy release is proposed to assess the rock brittleness. It is found that increasing water content is to relieve energy release and catastrophe failure of the rock specimen, and weakening the capacity of elastic energy storage. The peak and residual values of elastic energy are raised as the confining pressure increases, and the post-peak released energy decreases progressively. The confining pressure strengthens energy storage and inhibits energy release of the rock specimen, and saturation of rock will weaken this inhibit effect. The brittleness index decreases with increasing confining pressure as the rock specimen transforming from brittle to ductile.
\end{abstract}

Keywords: Sandstone; Energy release; Water content; Confining pressure

\section{INTRODUCTION}

\section{INTRODUCTION}

Sandstone as a kind of building material is often used in the foundation engineering of coast, river bank and lake shore. The deformation and failure of sandstone is influenced by the water content, loading and unloading conditions, etc. Since the deformation and failure of the sandstone is a comprehensive result of energy release and dissipation, the energy released in the sandstone plays a pivotal role of abrupt global failure [1]. The elastic strain energy is gradually stored in the rock system by the applied external force, and then transmitted to the engineering surrounding rock when reaching its storage limit. Sudden release of the elastic energy seriously threatens the rock excavation security. So, it is instructive and practically useful to research on the nature of energy release of the sandstone specimen $[2,3]$.

Now many studies have been conducted for the laws of energy revolution of different rock specimens, such as Z. Z. Zhang and F. Gao conducted uniaxial cyclic loading tests on red sandstone specimens, indicated that non-linear characteristics exsit in the energy conversion mechanism [4]. F. K. Xiao et al. performed cyclic unloading tests on coal specimens to analyze the correlation between the released elastic energy and force drop time [5]. D. Huang et al. conducted triaxial unloading tests on marble specimens, they concluded that magnitude of initial confining pressure 
and unloading rate significantly influence strain energy conversion [6]. M. N. Bagde and V. Petroš investigated the energy behavior of different rock specimens subjected to cyclical loading [7]. These studies cited above primarily focus on the energy properties of the specimens subjected to uniaxial, triaxial compression or cyclic loading. However, the force applied to the rock masses is often step incremental as the excavation engineering carried out in field, usually functions as rating loading and unloading. D. Z. Song and $X$. S. Liu et al. investigated the energy dissipation of rock specimens under rating loading and unloading condition respectively $[8,9]$, but these discussions didn't consider the energy release behavior in the loading type in details.

Water content and confining pressure are important factors influencing the post-peak mechanical response of the rock specimen. B. Vásárhelyi and I. Yilmaz et al. studied the influence of water content on the strength and deformability of sandstone and gypsum specimens [10, 11]. M. Duda and J. Renner performed triaxial compression experiments on sandstone to identify the weakening effect of water on the strength and brittle characteristics of rock [12]. The previous studies mainly focused on the strength and deformation properties of dry and saturated rock specimens and neglected the influence of varied water content on energy behavior. J. P. Zuo et al. analyzed the stress drop of rock specimens in post-peak range from energy view, the coefficient of energydrop was presented to discuss the variation of rock failure from brittle to ductile and the confining pressure effect on it [13]. B. Tarasov and Y. Potvin estimated rock brittleness based on the elastic energy accumulated and released within the loaded specimen and analyzed the confining pressure effect on rock brittleness [14]. W. Sukplum investigated the mechanical deformation properties of sandstone with cyclic loading in uniaxial and triaxial compression tests, and they found that the confining pressure has a significant effect on deformation, higher confining pressure results in larger strains [19].

The presented results imply that the confining pressure exerts influence on brittle character and energy storage and release of rock specimens. Deformation and failure of the rock specimens are often accompanied with energy release behavior and exhibits remarkable non-linear characteristics [4]. The sudden release of elastic energy of the rock specimen is a typical catastrophe process in the post-peak range, previous researches rarely involved this process. In this paper, a nonlinear model of released energy of the rock specimen, based on the energy revolution experiment on sandstone with different water content under rating loading and unloading, is designed to analyze the laws of released energy. The index for evaluating rock brittleness is proposed to reveal the effect of confining pressure on the released energy and transition from brittle to ductile. The results could deepen the understanding of energy release behavior of rock and provide beneficial reference for explaining brittle failure mechanism.

\section{EXPERIMENTAL SAMPLES AND LOADING EQUIPMENT}

The test specimens are Hawkesbury sandstone from Gosford quarry in Sydney, Australia. According to the standardization of laboratory tests specified by International Society for Rock Mechanics, the specimens were prepared as $\Phi 46 \mathrm{~mm} \times 100 \mathrm{~mm}$ right circular cylinders in the laboratory of school of mining engineering, University of New South Wales in Australia. To reflect the influence of water content on the mechanical response and energy character of sandstone, four groups of specimens were prepared with water content of $0 \%, 25 \%, 50 \%$, and 100 $\%$, four specimens constitute each group.

The test was carried out on the MTS- 815 servo controlled testing system. Firstly, the uniaxial compressive strength was determined, programming the axial force to increase with time at a loading rate of $0.05 \mathrm{kN} / \mathrm{s}$. Then rating loading and unloading was applied to the specimen until failure, the realtime axial load and deformation were recorded automatically throughout the whole test. The stress of each unloading point in pre-peak range is $60 \%, 72 \%, 84 \%$, and $96 \%$ of the uniaxial compressive strength, and all unloaded to $10 \%$ of the uniaxial compressive strength. In order to obtain the confining pressure effect on energy revolution of the rock specimen, triaxial tests at confining pressures of $0 \mathrm{MPa}, 2.5 \mathrm{MPa}, 5.0 \mathrm{MPa}$, and $7.5 \mathrm{MPa}$ were performed.

\section{RESULTS AND DISCUSSION}

\section{CATASTROPHE CHARACTERISTICS ANALYSIS FOR RELEASED ENERGY OF THE ROCK SPECIMEN}

The stress-strain response of dry sandstone specimens subjected to rating loading and unloading is illustrated in Fig. 1. Using the unloading modulus and stress value, the elastic energy $U_{e}$, at each unloading point and post-peak recorded point can be calculated [1]. Fig. 2 shows the curve of energy $U_{\mathrm{e}}$ varying against axial $x$-displacement. Fitting the calculated value of $U_{\mathrm{e}}$ with $x$-displacement, we can found that the quartic polynomial has the highest effect. The laws of elastic energy revolution could be accurately described by the fitting curves and equations as shown in Fig. 3.

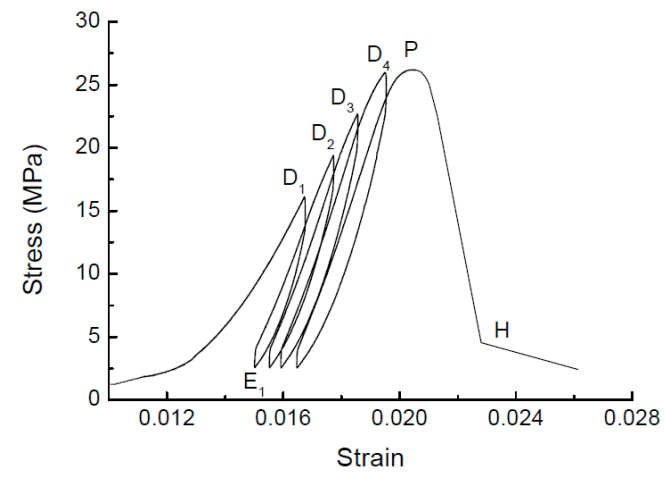

Fig. 1. Stress-strain curve of the dry specimen with rating loading and unloading 


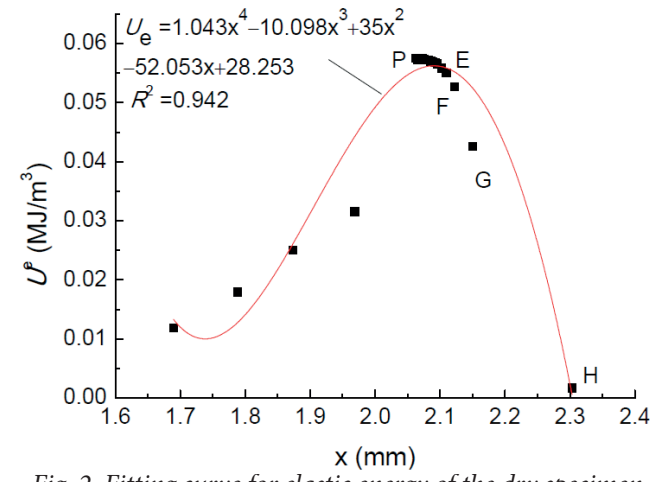

Fig. 2. Fitting curve for elastic energy of the dry specimen

a) $25 \%$

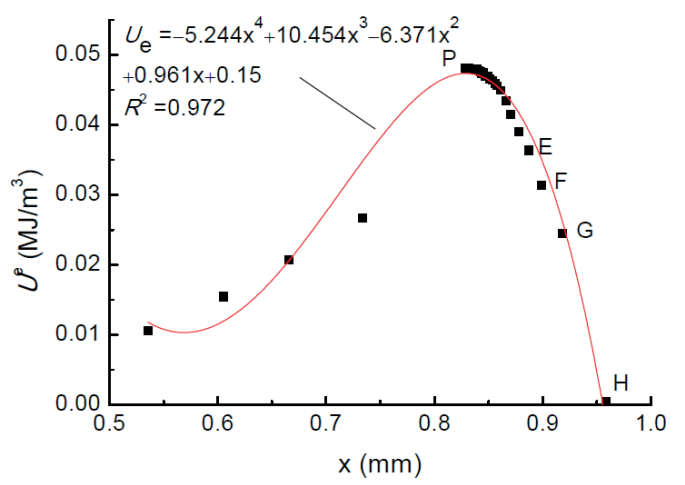

b) $50 \%$

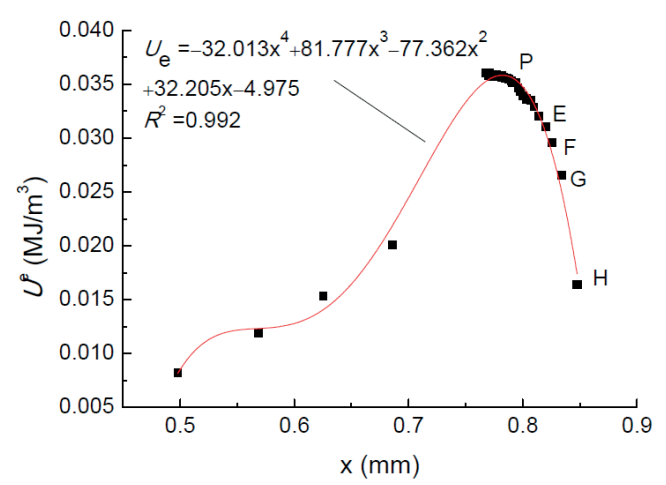

c) $100 \%$

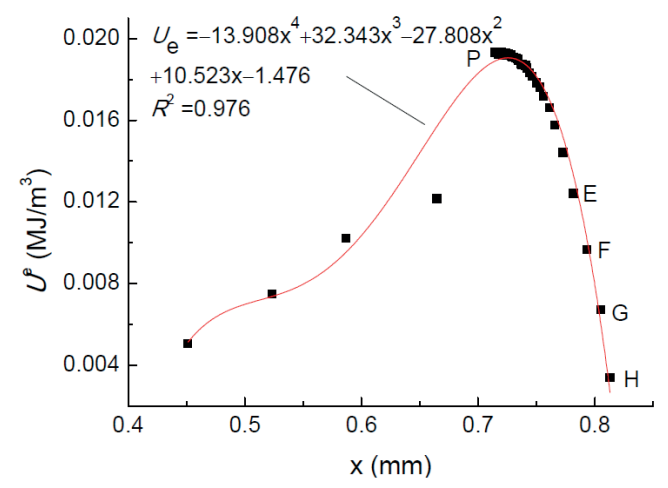

Fig. 3. Fitting curves for elastic energy of the specimens with different water contents

The difference $\Delta U^{e}$ is used to represent the elastic energy increase between two adjacent recorded points. As illustrated in Fig. 2, the pre-peak value of $U^{e}$ keeps increasing, $\Delta U^{e}>0$ the elastic energy is in a state of accumulation. Point $\mathrm{P}$ is the initiation of a mass released energy, thereafter $\Delta U^{e}<0$. Each point in section PE is closely neighbored and the value of $\Delta U^{e}$ is quite little, the energy exhibits a progressive release. Before point $\mathrm{H}$ the value of $\Delta U_{E F}^{e}, \Delta U_{F G}^{e}$ and $\Delta U_{G H}^{e}$ is $-0.0024 \mathrm{~J} / \mathrm{m}^{3}$, $-0.0101 \mathrm{MJ} / \mathrm{m}^{3}$, and $-0.0409 \mathrm{MJ} / \mathrm{m}^{3}$, respectively, the released energy in each equal time increases dramatically, global failure of the rock specimen occurs at point $\mathrm{H}$ and the energy release is terminated. This is a typical catastrophe process in which the elastic energy exhibits a sudden release in a large amount.

The cusp catastrophe model can be used in analyzing the sudden changes in elastic energy of the rock specimen. The original function of fitting equations in Figs. 2 and 3 is given by

$$
U^{e}=a_{1} x+a_{2} x^{2}+a_{3} x^{3}+a_{4} x^{4}+a_{0}
$$

where $a_{1}, a_{2}, a_{3}, a_{4}$ are coefficients determined by fitting.

Let $x=u-t, t=\frac{a_{3}}{4 a_{4}}$, then the potential function of the model is given by

$$
V(u)=u^{4}+p u^{2}+q u+C
$$

where $p=\frac{a_{2}}{a_{4}}-\frac{3 a_{3}^{2}}{8 a_{4}^{2}}, q=\frac{a_{1}}{a_{4}}-\frac{a_{2} a_{3}}{2 a_{4}^{2}}+\frac{a_{3}^{3}}{8 a_{4}^{3}}, C$ is a constant term.

Consequently, combining the equation of curved surface of equilibrium $V^{\prime}(u)=0$ and singular points set $V^{\prime \prime}(u)=0$, the bifurcation set is expressed as

$$
\Delta=8 p^{3}+27 q^{2}
$$

Eq. (3) can be used as the stability criterion for model equilibrium, as $\Delta>0$, progressive system revolution in stable equilibrium, $\Delta=0$ represents the neutral equilibrium, if $\Delta<0$, catastrophe instability occurs.

After the fitting parameters being introduced into Eqs. (2) and (3), the calculated results are listed in Tab. 1.

Tab. 1. Relative parameters of the model for elastic energy of the rock specimens

\begin{tabular}{ccccc}
\hline $\begin{array}{l}W_{\mathrm{C}} \\
(\%)\end{array}$ & $\begin{array}{c}\left|\Delta U_{E F}^{e}\right| \\
\left(\mathrm{MJ} / \mathrm{m}^{3}\right)\end{array}$ & $\begin{array}{c}\left|\Delta U_{F G}^{e}\right| \\
\left(\mathrm{MJ} / \mathrm{m}^{3}\right)\end{array}$ & $\begin{array}{c}\left|\Delta U_{G H}^{e}\right| \\
\left(\mathrm{MJ} / \mathrm{m}^{3}\right)\end{array}$ & $\frac{\Delta U_{G H}^{e}}{\Delta U_{E F}^{e}}$ \\
\hline 0 & 0.0024 & 0.0101 & 0.0409 & 4.05 \\
25 & 0.0050 & 0.0069 & 0.0241 & 4.08 \\
50 & 0.0015 & 0.0030 & 0.0102 & 3.4 \\
100 & 0.0027 & 0.0029 & 0.0033 & 1.14 \\
\hline
\end{tabular}


The control variable $p$ of the specimens with different water contents is all below zero, satisfying necessary conditions of cusp catastrophe. The values of criteria $\Delta$ for the specimens with water content of $0 \%, 25 \%$, and $50 \%$ are all below zero. As illustrated in Tab. 1, for the points E, F, G, H recorded by equal time interval, the energy released in equal time of the first three kind specimens multiples before the residual point $\mathrm{H}$, showing remarkable catastrophe characteristics. The value of criteria $\Delta$ for the saturated specimen is 0.000237 , as shown in Fig. $3 \mathrm{c}$ and Tab. 1, the released energy in unit time is nearly equal, not appearing catastrophe phenomenon. It is found that the absolute value of criteria $\Delta$ and the released energy decrease constantly with water content increasing, the value of $\Delta$ for the saturated specimen is greater than zero, the released energy transforms from catastrophe to progressive type. Hence, the increase in water content inhibits catastrophe instability and energy release in this type of failure.

\section{THE BRITTLENESS INDEX OF ROCK BASED ON ENERGY RELEASE}

Brittle failure is the dynamic instability induced by release of the energy stored in rock, the released energy for deformation and failure of the rock specimen can be used to evaluate rock brittleness. It is the instability stage in post-peak range from point $\mathrm{P}$ to $\mathrm{H}$, as shown in Figs. 2 and $3, \Delta U^{e}<0$ , the relative magnitude of the released energy in this stage, $R$, is given by

$$
R=\frac{\left|\Delta U_{P H}^{e}\right|}{U_{P}^{e}}=\frac{U_{P}^{e}-U_{H}^{e}}{U_{P}^{e}}
$$

In Eq. (4):

$U_{P}^{e}-$ The elastic energy at the peak point $\mathrm{P}, \mathrm{MJ} / \mathrm{m}^{3}$;

$U_{H}^{e}{ }^{--}$The elastic energy at the residual point $\mathrm{H}, \mathrm{MJ} / \mathrm{m}^{3}$;

$\left|U_{P H}^{e}\right|--$ The absolute value of elastic energy increment in range $\mathrm{PH}, \mathrm{MJ} / \mathrm{m}^{3}$.

Using the peak strain $\varepsilon_{P}$ and residual strain $\varepsilon_{H}$, the brittleness index $K$ is given by

$$
K=\frac{R}{\varepsilon_{H}-\varepsilon_{P}}=\frac{U_{P}^{e}-U_{H}^{e}}{U_{P}^{e}\left(\varepsilon_{H}-\varepsilon_{P}\right)}
$$

The higher value of $K$ marks the brittle behavior of rock in the post-peak range. The area between the post-peak stressstrain curve and horizontal axis represents the external work $\Delta S$. If $K \rightarrow \infty$, then $\Delta S \rightarrow 0$, it is indicated that the component of energy that can dissipate for fracture is mainly the elastic energy stored in the rock specimen, the violet released energy leads to sudden failure which approaches to ideal brittle. Decreasing value of $K$ implies more external work needs to be input for rock failure, the brittleness is weakened, as $K \rightarrow 0$, the failure approaches ideal plastic. So the index $K$ can be used to evaluate rock brittleness.

\section{WATER CONTENT ANALYSIS FOR INFLUENCE ON ENERGY RELEASE}

As shown in Fig. 4, the released energy of rock specimens with different water content were calculated by the computational method [1] and the unloading modulus obtained from rating loading test. The violet release of elastic energy during failure process makes a remarkable drop of the post-peak curve. With decreasing water content, the peak values of elastic energy keep increasing, the peak point $P$ and residual point $\mathrm{H}$ advance gradually, the rock saturation can weaken the pre-peak accumulation of elastic energy.

Using the peak and residual elastic energy of the rock specimens in triaxial compression, the relative value of post-peak released energy, $R$, was calculated by Eq. (4). As illustrated in Fig. 5, the index $R$ remains essentially unchanged as the water content $W_{\mathrm{C}}$ varied from $0 \%$ to $25 \%$ and then decreases with $W_{C}$ increasing, the value of $R$, compared with the dry state, is reduced more than $20 \%$ as the specimen is saturated.

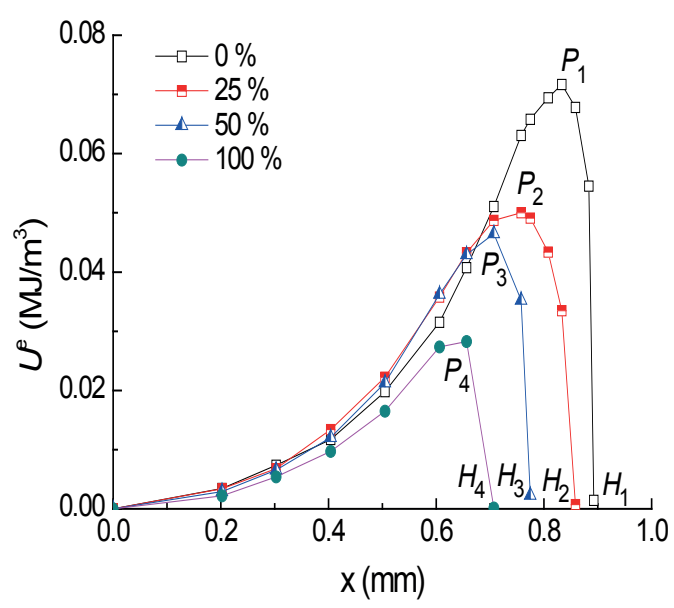

Fig. 4. Elastic energy curves of the specimens with different water contents

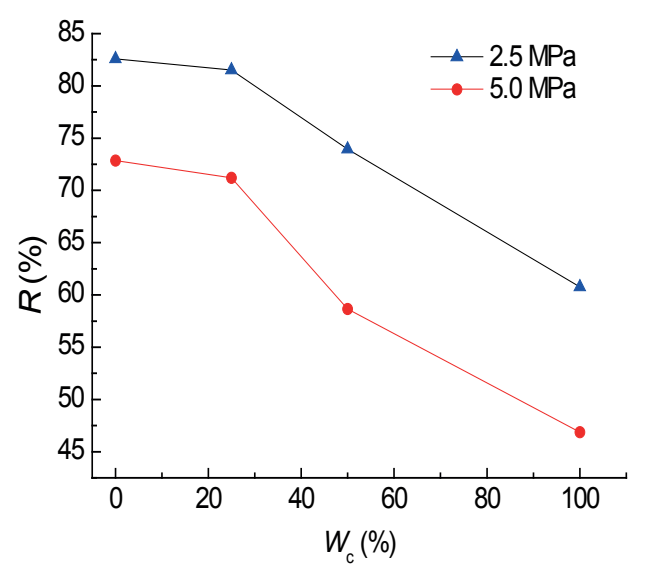

Fig. 5. Variation of the relative value of released elastic energy with water contents 


\section{EFFECT ANALYSIS OF CONFINING PRESSURE ON THE RELEASED ENERGY}

Taking the dry rock specimens as example, the elastic energy at different stress level in triaxial condition was calculated based on the stress-strain curve, as shown in Fig. 6. The peak and residual values of $U^{\mathrm{e}}$ are raised with confining pressure increasing, and the confining pressure strengthens the capacity of energy storage. The elastic energy of the rock specimen in uniaxial compression decreases dramatically in the post-peak range and the residual value approaches to zero, with increasing confining pressure, the post-peak curve of $U^{\mathrm{e}}$ is changed from steep to flatter.

The relative magnitude of released energy, $R$, was calculated by Eq. (4) using the values of $U_{P}^{e}$ and $U_{H}^{e}$ with different confining pressure $C_{\mathrm{f}}$. Fig. 7 shows that the index $R$ monotonically decreases with $C_{\mathrm{f}}$, the average value of $R$ at the confining pressures of $0 \mathrm{MPa}, 2.5 \mathrm{MPa}, 5.0 \mathrm{MPa}$, and $7.5 \mathrm{MPa}$ is $97.58 \%, 73.95 \%, 59.64 \%$, and $50.13 \%$, corresponding to different water content of $0,25 \%, 50 \%$, and $100 \%$. The confining pressure markedly inhibits energy release of rock. As the confining pressure changed from 0 $\mathrm{MPa}$ to $2.5 \mathrm{MPa}$, the reduction of $R$ is most significant in the saturated specimen. With the confining pressure increasing, the reduction tends to slow down in the specimens with water. It should be noted that the index $R$ decreases linearly with $C_{\mathrm{f}}$ in the dry specimen, and turning to decrease nonlinearly as exponential law with water content increasing. So, the saturation of rock weakens the inhibiting effect of confining pressure on energy release.

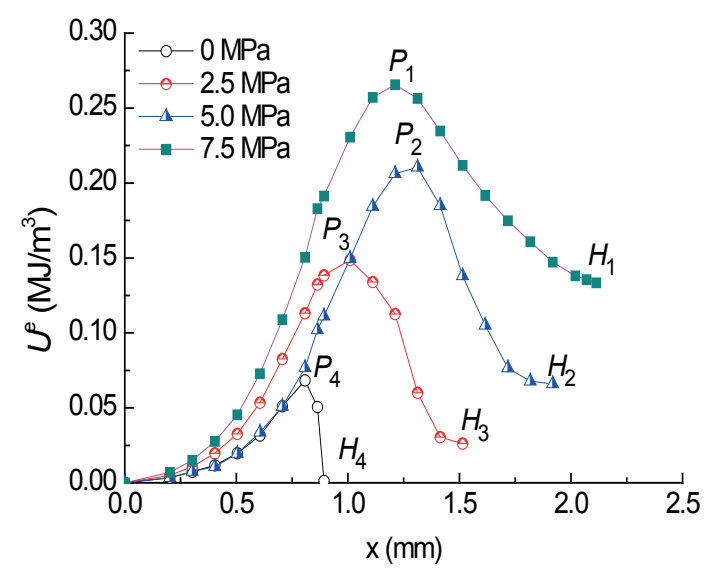

Fig. 6. Elastic energy curves of the dry specimens with different confining pressures

As shown in Figs. 8 and 9, the value of index $K$ is 3368.5 and post-peak external work approaches zero, the violet released energy leads to stress drop which marks remarkable brittle failure character. As the confining pressure increased from $2.5 \mathrm{MPa}$ to $7.5 \mathrm{MPa}$, the value of $K$ decreases gradually with a transition of the rock specimen from brittle to ductile, the brittleness is weakened markedly compared with uniaxial compression condition, low value of $K$ represents strong ductility. The brittleness index $K$ can be used in evaluating the brittle and ductile behavior of the rock specimen and reflecting the transition trend caused by confining pressure.

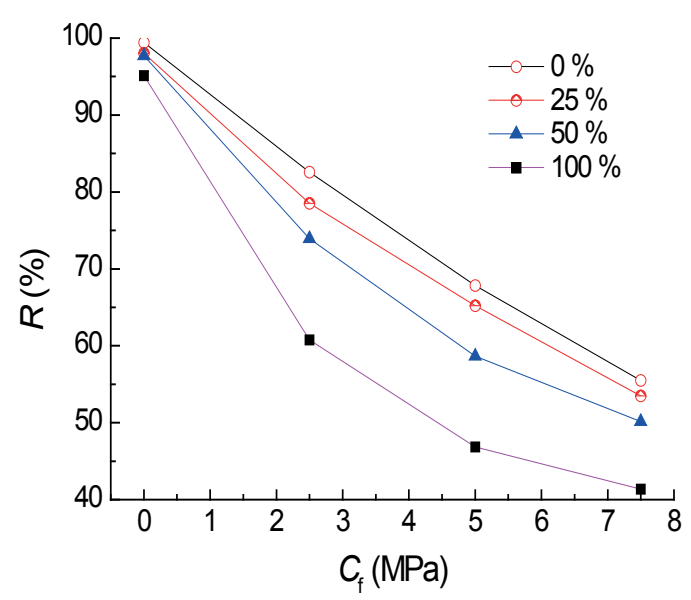

Fig. 7. Variation of the relative value of released elastic energy with confining pressure

\section{DISCUSSION}

The results of rating loading and unloading test are analyzed to investigate the post-peak energy release behavior of the water-baring sandstone. The instability criterion of the specimen is proposed based on the cusp catastrophe model and used to forecast the sudden changes in elastic energy. The chaos model was established to discuss the pre-peak energy conversion mechanism of the sandstone specimen [4], not relating the released energy and its non-linear characteristics in the post-peak stage. A supplementary analysis for this content was conducted by the cusp catastrophe model designed in this paper, further research is needed to verify whether it is suitable for other loading path. The energy dissipation of the rock specimen subjected to cyclic loading was investigated $[8,9]$, we can see that the water content has a remarkable influence on the released energy of the rock specimen.

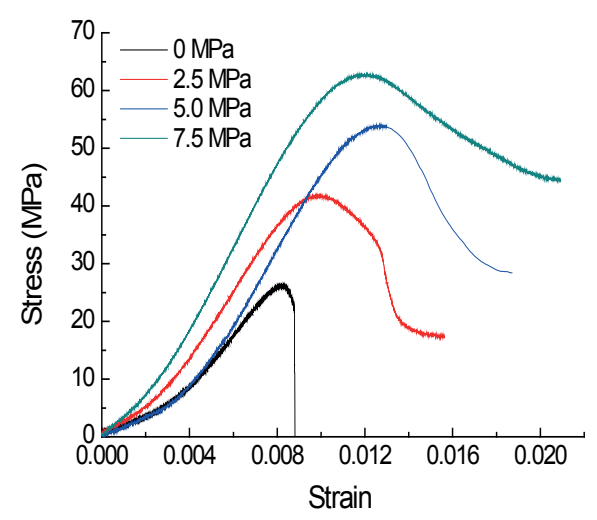

Fig. 8. Stress-strain curves of the dry specimen with different confining pressures 


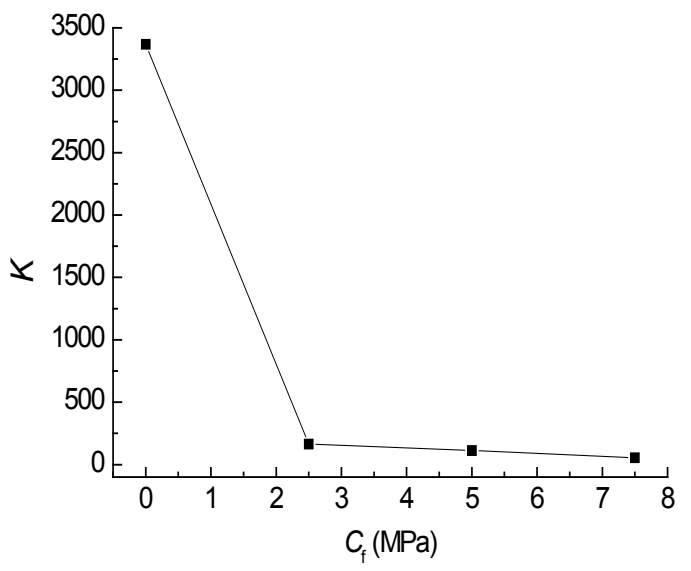

Fig. 9. Variation of brittleness index of the dry specimen with confining pressure

The relative magnitude of the released energy, $R$, decreases markedly as the confining pressure varied from $0 \mathrm{MPa}$ to $7.5 \mathrm{MPa}$, and $R$ corresponding to different water content is reduced $24.2 \%$ on average, the reduction value for the saturated specimen is most remarkable. The decreasing trend of $R$ is changed from linear to exponential law by increasing water content. The transition of rock from brittle to ductile with confining pressure increasing was discussed using the energy-drop coefficient proposed [13], but the analysis is lack of consideration for energy release, for the energy release is the key factor of brittle failure. The brittleness index based on the released energy of rock is proposed in this paper, and can be used in describing the brittle and ductile behavior of the water-baring sandstone.

\section{CONCLUSIONS}

The catastrophe model of energy accumulation and release is established using the fitting equations of released energy of the rock specimens in rating loading and unloading test. It is possible to predict sudden changes in post-peak elastic energy based on the instability and catastrophe criteria. The model is suitable for analyzing the energy release behavior of rock failure.

Water content increasing can inhibit the catastrophe change of elastic energy in the post-peak stage, and the peak and residual energy decreases with water content increasing. The saturation of rock weakens the capacity of storing energy and reduces the released energy for rock failure, making the relative magnitude of released energy exponentially decrease with confining pressure.

The peak and residual elastic energy of rock progressively increase with the confining pressure increasing, and the confining pressure strengthens the capacity of storing energy and inhibits energy release in post-peak stage. The proposed brittleness index can evaluate the brittleness degree of rock and reflect the confining pressure effect on the transition behavior from brittle to ductile.

\section{ACKNOWLEDGEMENTS}

This project is financially supported by the National Natural Science Foundation of China (51474188), the International Cooperation Project of Henan Science and Technology Department (162102410027), the Doctoral Fund of Henan Polytechnic University (B2015-67), the research fund of Henan Key Laboratory for Green and Efficient Mining \& Comprehensive Utilization of Mineral Resources, and Taihang Scholars Program. All these are gratefully appreciated.

\section{BIBLIOGRAPHY}

1. Xie, H.P., Ju, Y., Peng, L.Y.: Criteria for strength and structural failure of rocks based on energy dissipation and energy release principles, Chinese Journal of Rock Mechanics \& Engineering, Vol. 24, no 17, pp. 3003-3010, 2005.

2. Chen, X.G., Zhang, Q.Y.: Research on the energy dissipation and release in the process of rock shear failure, Journal of Mining \& Safety Engineering, Vol. 27, no 2, pp. 179-184, 2013.

3. Xue, D.J., Zhou, H.W., Zhong, J.C., Huang, Y.M.: Mininginduced release of energy from rock and mechanism on catastrophic failure, Chinese Journal of Rock Mechanics \& Engineering, Vol. 33, no S, pp. 3865-3872, 2014.

4. Zhang, Z.Z., Gao, F.: Research on nonlinear characteristics of rock energy evolution under uniaxial compression, Chinese Journal of Rock Mechanics \& Engineering, Vol. 31, no 6, pp. 1198-1207, 2012.

5. Xiao, F.K., Liu, G., Shen, Z.L.: Research on effective elastic energy release rate of taoshan \#90 coal seam, Chinese Journal of Rock Mechanics \& Engineering, Vol. 34, No $\mathrm{S}_{2}$, pp. 4216-4225, 2015.

6. Huang, D., Li, Y.R.: Conversion of strain energy in triaxial unloading tests on marble, International Journal of Rock Mechanics \& Mining Sciences, Vol. 66, No 1, pp. 160-168, 2014.

7. Bagde, M.N., Petroš, V.: Fatigue and dynamic energy behaviour of rock subjected to cyclical loading, International Journal of Rock Mechanics \& Mining Sciences, Vol. 46, No 1, pp. 200-209, 2009.

8. Liu, X.S., Ning, J.G., Tian, Y.L., Guo, Q.H.: Damage constitutive model based on energy dissipation for intact rock subjected to cyclic loading, International Journal of Rock 
Mechanics \& Mining Sciences, Vol. 85, pp. 27-32, 2016.

9. Song, D.Z., Wang,E.Y., Liu, J.: Relationship between EMR and dissipated energy of coal rock mass during cyclic loading process, Safety Science, Vol. 50, no 4, pp. 751-760, 2012.

10. Vásárhelyi, B., Ván, P.: Influence of water content on the strength of rock, Engineering Geology, Vol. 84, No 1-2, pp. 70-74, 2006.

11. Yilmaz, I.: Influence of water content on the strength and deformability of gypsum, International Journal of Rock Mechanics \& Mining Sciences, Vol. 47, no 2, pp. 342-347, 2010.

12. Duda, M., Renner, J.: The weakening effect of water on the brittle failure strength of sandstone, Geophysical Journal International, Vol. 192, no 3, pp. 1091-1108, 2013.

13. Zuo, J.P., Huang, Y.M., Xiong, G.J., Liu, J., Li, M.M.: Study of energy-drop coefficient of brittle rock failure, Rock \& Soil Mechanics, Vol. 35, no 2, pp. 321-327, 2014.

14. Tarasov, B., Potvin, Y.: Universal criteria for rock brittleness estimation under triaxial compression, International Journal of Rock Mechanics \& Mining Sciences, Vol. 59, no 4, pp. 57-69, 2013.

15. Sukplum, W., Wannakao, L.: Influence of confining pressure on the mechanical behavior of Phu Kradung sandstone, International Journal of Rock Mechanics \& Mining Sciences, Vol. 86, pp. 48-54, 2016.

\section{CONTACT WITH THE AUTHOR}

Shuren Wang, Ph.D., Prof.

e-mail:w_sr88@163.com

International Joint Research Laboratory of Henan Province for Underground Space Development and Disaster Prevention

Henan Polytechnic University Jiaozuo Henan

454003 CHINA 